\title{
Elaboração e aplicação dos indicadores de sustentabilidade em pequenas e médias empresas
}

\begin{abstract}
RESUMO
Este texto tem como propósito descrever os procedimentos operacionais para a elaboração de um relatório de sustentabilidade para pequenas e médias empresas, com base nas diretrizes do Global Reporting Initiative (GRI). O estudo foi desenvolvido em uma empresa prestadora de serviços localizada na cidade de Chapecó/SC. Trata-se de uma pesquisa descritiva e qualitativa, e cuja coleta de dados empíricos foi feita no primeiro semestre de 2014. Foi constatado que o grau de dificuldade para a elaboração de um relatório de sustentabilidade em uma pequena empresa é grande, haja vista não haver recursos humanos disponíveis para monitorar os indicadores. Para obter êxito, é necessário comunicar a equipe da importância e necessidade de acompanhar os indicadores de desempenho das áreas econômica, social e ambiental. Além disso, o estratégico da organização precisa estar diretamente envolvido, para que seja possível obter a legitimidade da ideia no contexto organizacional. Sugere-se criar um comitê de sustentabilidade, coordenado pelo diretor da empresa, a fim de que este promova o engajamento de todos os colaboradores para a criação de uma cultura sensibilizada com as práticas de sustentabilidade. O passo seguinte é a realização de treinamentos e monitoramento dos indicadores relevantes para a gestão. Em seguida, devem-se fazer os registros e tabulá-los em formato de relatório, para posterior comunicação a todas as partes interessadas. Como ferramenta, adotar planilhas Excel, que evidenciam os indicadores, sua métrica de mensuração e o desempenho atingido pela organização mês a mês. De posse dos dados, é possível elaborar o relatório de sustentabilidade e criar metas de melhoria contínua.
\end{abstract}

Palavras-chave: Sustentabilidade. Global Reporting Initiative. Relatório de sustentabilidade.

Simone Sehnem

Maiara Cristina Lukas 


\section{INTRODUÇÃO}

Conforme Abdalla e Feichas (2005), o Brasil e a Suécia têm em comum a grande quantidade de pequenas empresas, consideradas aquelas que possuem dificuldades para priorizar ações ambientais, mas que precisam aperfeiçoar seus processos produtivos em prol do meio ambiente, tendo em vista o potencial poluidor que têm em seu conjunto. Por outro lado, as pressões dos clientes, as leis e regulamentações, os competidores que já possuem certificações ambientais e os fornecedores são relevantes fatores que pressionam as empresas a procurar a certificação ISO 14.001 (HALLINAM; JENKS, 2004).

Nos últimos anos, os clientes criaram uma consciência maior acerca das questões relacionadas ao meio ambiente. Passaram, então, a cobrar das empresas iniciativas voltadas às questões ambientais. Quanto aos motivos alegados pelas empresas para adotarem a certificação, o principal foi a melhoria da imagem, seguido da melhora das relações com os clientes e a busca por nova clientela. Outras razões que corroboram para a adoção de iniciativas ambientais são a diminuição do impacto ambiental e o aprimoramento das relações com os outros integrantes da cadeia de produção (ABDALLA; FEICHAS, 2005).

Abdalla e Feichas (2005) destacam que, no médio e longo prazo, vale a pena investir em meio ambiente e responsabilidade social, pois, além do retorno do investimento, há outros ganhos relacionados à imagem, valorização da marca e conquista do mercado. Entretanto, com esse aumento da pressão externa que sobrevém às pequenas e médias empresas, há também dificuldades de ordem financeira para investimentos na melhoria de processos cujo retorno não é claramente percebido por seus proprietários e que só ocorrerá em médio e longo prazo.

Moura (2002) afirma que as características desejáveis nos indicadores de sustentabilidade consistem em pressupostos, metodologia, validade, relevância, viabilidade e comunicação. Callado e Fensterseifer (2009) destacam que os indicadores de sustentabilidade devem possuir as características de seletividade, representatividade, simplicidade, baixo custo, estabilidade, comparação externa e de melhoria contínua. Ademais, a seleção dos indicadores de sustentabilidade deve contemplar a relevância direta dos objetivos do projeto; limite ao número; clareza no delineamento; custos realistas no desenvolvimento; identificação clara das ligações causais; alta qualidade e confiabilidade; escala temporal e espacial apropriada; e objetivos e fundamentos (CALLADO; FENSTERSEIFER, 2009).

Bellen (2008), por sua vez, salienta que, se os indicadores de sustentabilidade forem utilizados para promover o desenvolvimento sustentável pelas organizações, devem ser compilados com cuidado para que possam contribuir na minimização das distorções nas informações geradas e tornarem-se mais habilitados a responder importantes questionamentos dos tomadores de decisões e de outros possíveis interessados. Portanto, monitorar os indicadores de sustentabilidade em empresas de pequeno e médio porte pode contribuir para a geração de um relatório importante para a tomada de decisão e, sobretudo, trazer uma vantagem competitiva para tais empresas. As empresas estão acompanhando as tendências de produção e consumo, e adequando-se ao que os consumidores e clientes prezam. Comunicar a situação atual da empresa no que tange aos aspectos ambientais, sociais e econômicos, seguindo a ferramenta Global Reporting Initiative (GRI), consiste em uma tarefa de transparência e ética, que aumenta o rigor, a qualidade e a utilidade de relatórios para a sustentabilidade corporativa.

Entretanto, o desafio com o qual as empresas se deparam é como fazer para implantar um relatório de sustentabilidade que siga as diretrizes do GRI. Baseado nesse pressuposto, a intenção da pesquisa consiste em elaborar um manual de procedimentos operacionais que facilite a compreensão da referida ferramenta e que auxilie no processo de monitoramento e mensuração dos indicadores ambientais, sociais e econômicos da organização. Callado e Fensterseifer (2009) reiteram que um dos principais desafios da criação de um desenvolvimento que rume em direção à sustentabilidade consiste em criar instrumentos de mensuração que associem variáveis de diversas esferas, revelando significados mais amplos sobre os fenômenos a que se referem. Por isso, os indicadores de sustentabilidade são instrumentos essenciais para guiar a ação e subsidiar o acompanhamento e a avaliação do progresso alcançado na direção do desenvolvimento sustentável.

Baseado nesse contexto, o problema de pesquisa consiste no seguinte: Quais os procedimentos operacionais para elaboração de um relatório de sustentabilidade para pequenas e médias empresas à luz das diretrizes da GRI? O objetivo principal da pesquisa é descrever os procedimentos operacionais para a elaboração de um relatório de sustentabilidade para pequenas e médias empresas, pautado nas diretrizes do GRI. Os objetivos específicos consistem em analisar as diretrizes do GRI com a finalidade de elaborar um manual de procedimentos operacionais para implantação de um relatório de sustentabilidade em pequenas e médias empresas; identificar indicadores de fácil monitoramento e mensuração nas empresas, e detalhar a forma como tais indicadores podem ser calculados para 
empresas industriais e para prestadoras de serviços; apresentar formulários/planilhas de controle para geração de indicadores que permitam elaborar um relatório de sustentabilidade em pequenas e médias empresas industriais e prestadoras de serviços; validar o manual de procedimentos operacionais em uma empresa de pequeno ou médio porte.

Considerando as dificuldades que as pequenas e médias empresas passam para elaborar um relatório de sustentabilidade, foram elencadas algumas dúvidas que constantemente assolam os empresários: (1) Como implantar um relatório de sustentabilidade que siga as diretrizes do GRI? (2) Como mensurar os aspectos ambientais, sociais e econômicos em uma pequena e média empresa? (3) Uma empresa prestadora de serviços pode fazer um relatório de sustentabilidade pautado nas diretrizes do GRI?

O principal impacto decorrente do desenvolvimento desta proposta de pesquisa consiste em colaborar para tornar as pequenas e médias empresas competitivas no quesito da sustentabilidade. Ou melhor, que a sustentabilidade seja um aspecto valorado, mensurado e divulgado por essas empresas, pois estudos secundários comprovam que essa avaliação é importante para a reputação das empresas, para a obtenção de vantagem competitiva e para atender às demandas de clientes e de requisitos legais.

A forma de apropriação dos resultados da pesquisa em termos científicos e acadêmicos consiste em realizar um estudo dos dados bibliográficos disponíveis em bases de dados científicas e que versam a respeito de relatórios de sustentabilidade e suas implicâncias para a teoria e para a prática organizacional. Em termos tecnológicos, sociais e ambientais, o estudo gerará resultados positivos a todos os atores envolvidos (empresa, sociedade e meio ambiente) por meio da inculturação de princípios de desenvolvimento que primem pela valorização social e pelo sustentar-se ao longo do tempo, valorando os recursos naturais. As ações de disseminação dos resultados da pesquisa serão efetuadas por meio dos seminários de pesquisa promovidos pela Universidade do Oeste de Santa Catarina(UNOESC). Se for de interesse da Federação das Indústrias de Santa Catarina(FIESC), será efetuada apresentação nas reuniões dessa entidade, para socialização dos resultados para os associados.

Quanto à aplicabilidade regional, a pesquisa é relevante, pois atende a uma lacuna existente até o momento, já que somente grandes empresas têm efetuado relatórios de sustentabilidade. As demais consideram os indicadores complexos, de difícil monitoramento e controle dentro das organizações. A partir do momento em que tiverem à disposição um manual de procedimentos operacionais, será muito mais fácil viabilizar a adoção de um relatório de sustentabilidade.

\section{REFERENCIAL TEÓRICO}

Conforme Almeida Júnior e Gomes (2012), muitas empresas perceberam que enfrentar as questões ambientais é uma estratégia para fortalecer suas posições de mercado por meio da redução de custo de produção, do desenvolvimento de novos produtos e da melhoria da imagem corporativa. Melhorias voltadas ao meio ambiente tornaram-se, em algumas empresas, um estímulo para a inovação tecnológica. Igualmente, tornaram-se estímulo para o aprimoramento de técnicas de gerenciamento de imagem e fonte de vantagem competitiva.

Entretanto, para impactar na imagem das organizações, tornou-se primordial divulgar para todos os stakeholders as práticas de sustentabilidade adotadas pelas empresas. Há diversas ferramentas utilizadas para a mensuração da sustentabilidade, a exemplo do Global Reporting Initiative (GRI), Dashboard of Sustainability, Dow Jones Sustainability World Index (DJSI World), Instituto Brasileiro de Análises Sociais e Econômicas (Ibase), Instituto Brasileiro de Geografia e Estatística (IBGE), Instituto Ethos de Empresas e Responsabilidade Social e Instituto Akatu pelo Consumo Consciente. Internacionalmente, possui maior aceitabilidade e reconhecimento o GRI (CALLADO; FENSTERSEIFER, 2009).

Veleva e Ellenbecker (2000) salientam que os indicadores de sustentabilidade tentam identificar objetivamente se uma empresa está aproximando-se ou afastando-se das dimensões econômica, social e ambiental da sustentabilidade. Moura (2002) complementa, esclarecendo que indicadores são um conjunto de parâmetros que permitem medir as modificações antrópicas em determinado sistema e comunicar, de maneira simplificada, o estado desse sistema em relação aos critérios e às metas estabelecidas para avaliar a sua sustentabilidade.

Bellen (2008) reitera que os indicadores procuram comunicar o progresso em direção a uma meta, de forma simples e objetiva o suficiente para retratar o mais próximo da realidade, mas dando ênfase aos fenômenos que tenham ligações entre a ação humana e suas consequências. Da mesma forma, os indicadores indicam o modo como a empresa contribui ou pretende contribuir para a 
Simone Sehnem; Maiara Cristina Lukas; Patrícia do Desterro Marques

melhoria das condições econômicas, ambientais e sociais, no âmbito local, regional ou global.

A estrutura de sustentabilidade do GRI (CALLADO; FENSTERSEIFER, 2009) contempla as dimensões econômica, ambiental e social. Na dimensão econômica, na categoria impactos econômicos diretos, são avaliados os aspectos clientes, fornecedores, funcionários, investidores e setor público. Além disso, avaliam-se o desempenho econômico, a presença no mercado, os impactos econômicos indiretos e as práticas de compra. Na dimensão ambiental, na categoria impactos ambientais, são avaliados os aspectos materiais, energia, água, biodiversidade, emissões e resíduos, fornecedores, produtos e serviços, adequação à legislação e transporte.

$\mathrm{Na}$ dimensão social, as categorias de análise são práticas trabalhistas, direitos humanos, sociedade e responsabilidade sobre produtos e serviços. No que diz respeito às práticas trabalhistas, os aspectos avaliados são emprego, relações com funcionários, saúde e segurança, treinamento e educação, diversidade e oportunidade. Quanto aos direitos humanos, os aspectos avaliados são estratégia e gestão, não discriminação, liberdade de associação e de negociação coletiva, trabalho infantil, trabalho forçado e compulsório, procedimentos disciplinares, procedimentos de segurança e direitos indígenas. Sobre a categoria sociedade, são avaliados os aspectos comunidade, suborno e corrupção, contribuições políticas, competição e política de preços. Acerca da categoria responsabilidade sobre produtos e serviços, os aspectos avaliados são saúde e segurança dos consumidores, produtos e serviços, propaganda e respeito à privacidade.

Considerando o contexto da sustentabilidade, no qual além das diretrizes do GRI há outras métricas e dimensões de análise, Bellen (2008) afirma que, na medida em que os indicadores de sustentabilidade forem conhecidos e aceitos, tanto internacional como nacionalmente, podem tornar-se componentes fundamentais da agenda pública e social para o desenvolvimento, iniciando um processo eficaz de mudança de prioridades e de comportamento dos diversos atores sociais.

Entretanto, Hahn e Lulfs (2014) destacam que se pressupõe que os relatórios de sustentabilidade corporativa fornecem uma visão completa e equilibrada do desempenho sustentável empresarial de uma organização. Todavia, geralmente são desenvolvidos de forma voluntária e, consequentemente, propensos à interpretação e até mesmo a tendências de greeenwashing. Para superar esse problema, o GRI fornece diretrizes para elaboração de relatórios padronizados e desafia as empresas a relatar aspectos positivos e negativos do seu desempenho em sustentabilidade. Contudo, o relato de aspectos negativos pode pôr em perigo a legitimidade das empresas se percebida pelas partes interessadas como não estando em conformidade com as normas da sociedade e seus valores.

Milne e Gray (2013) sustentam que o tripple bottom line e as diretrizes do GRI são condição suficiente para as organizações contribuírem para a manutenção do equilíbrio na terra. Toppinen et al. (2012) salientam que é crescente o número de empresas industriais que declaram a adoção das diretrizes do GRI para evidenciar a existência de verificação, a elaboração de relatórios para minimizar as críticas acerca das práticas de responsabilidade corporativa adotadas pela organização.

A criação e implementação de indicadores de sustentabilidade continua sendo uma área de conhecimento emergente, que necessita o desenvolvimento de mais pesquisas para que o conhecimento científico gerado torne-se mais robusto e consensual, visto que novos estudos geram resultados positivos a todos os atores envolvidos, quais sejam, empresas, sociedade e meio ambiente (SEARCY; KARAPETROVIC; MCCARTNEY, 2005). Bonacchi e Rinaldi (2006) corroboram com esse pensamento, salientando que, no que se refere à sustentabilidade, há uma necessidade de se identificar um padrão de medidas para cada indústria, sendo o grau de sustentabilidade entre as empresas uma característica que pode ser comparada por meio de tempo e espaço. Além disso, com base no padrão de medidas, criar um sistema de scores que permita correlacionar o desempenho de sustentabilidade empresarial com sua performance no mercado de capitais.

\section{METODOLOGIA}

A pesquisa foi desenvolvida no período de agosto de 2013 a julho de 2014. Para operacionalizála, foi efetuada a consulta ao site do GRI, para ter acesso aos indicadores contemplados nessa ferramenta de mensuração da sustentabilidade. As etapas da pesquisa estão descritas a seguir:

$\left.1^{\circ}\right)$ Familiarização com os indicadores do GRI.

$2^{\circ}$ ) Criação de uma planilha contendo todos os indicadores por categoria (conteúdos de padrões gerais, aspectos materiais identificados e limites, engajamento de stakeholders, perfil do relatório, ética e integridade, indicadores econômicos, sociais e ambientais, direitos humanos, sociedade, saúde e segurança do cliente à luz das diretrizes do GRI).

$3^{\circ}$ ) Elaboração do manual de instruções prevendo o que precisa ser monitorado/mensurado, as etapas de monitoramento e mensuração desses indicadores em pequenas e médias empresas 
industriais e prestadoras de serviços. $O$ intuito da elaboração desse manual é simplificar a compreensão e o entendimento de cada um dos indicadores, e prever maneiras de contribuir para que pequenas e médias empresas também tenham acesso à publicação do seu desempenho em sustentabilidade.

$4^{\circ}$ ) Escolha de uma organização para servir de objeto de análise da pesquisa. Foi elegida, intencionalmente, uma empresa localizada na cidade de Chapecó/SC, sendo uma prestadora de serviços e que se manifestou disposta a implantar os indicadores de sustentabilidade, para fazer a validação do manual de procedimentos operacionais criados e identificar a sua exequibilidade. A escolha se deu a partir da participação no Fórum de lançamento dos Indicadores G4 (quarta versão dos indicadores GRI) na cidade de Chapecó, na qual o diretor-presidente da empresa escolhida manifestou interesse em adotar o relatório de sustentabilidade e em contribuir com esta pesquisa.

$5^{\circ}$ ) Agendamento de horário na empresa para discussão dos indicadores com a equipe pesquisada. Foi efetuada a apresentação da proposta de pesquisa e entregue um check list dos indicadores, para que a empresa pudesse relatar aqueles que são relevantes para a sua gestão.

$\left.6^{\circ}\right)$ Pesquisados tiveram um período de quinze dias para preencher a planilha com os dados e mapear os indicadores relevantes para a gestão da organização.

$\left.7^{\circ}\right)$ Recebimento das planilhas preenchidas.

$\left.8^{\circ}\right)$ Tabulação e análise dos dados.

Portanto, os indicadores do GRI englobam aspectos qualitativos e quantitativos, que são monitorados e mensurados por meio de métricas previamente estabelecidas no intuito de avaliar o nível de sustentabilidade da organização pesquisada.

O conjunto de indicadores foi elaborado em formato Excel e compilado neste artigo nos Quadros 1 a 9.

$\left.9^{\circ}\right)$ Reunião de socialização dos resultados na empresa pesquisada.

$10^{\circ}$ ) Elaboração do artigo derivado da pesquisa.

\section{APRESENTAÇÃO E ANÁLISE DOS RESULTADOS}

Esta seção descreve e analisa os dados da pesquisa que foram coletados em dados secundários e validados em uma empresa prestadora de serviços da região oeste de Santa Catarina.

\subsection{Diretrizes do GRI para elaborar um manual de procedimentos operacionais}

O GRI é uma Organização Não Governamental (ONG) sediada em Amsterdã. Foi criada em 1997, nos Estados Unidos, com base na ideia de que os relatos corporativos careciam de mais informações, além das financeiras. Dessa forma, criou-se uma rede de milhares de multi-stakeholders comprometidos em desenvolver um relatório que apresentasse indicadores de sustentabilidade. As diretrizes do GRI são um bem público, disponíveis para download gratuito. São atualizadas a cada dois anos. São desenvolvidas audiências públicas nas quais as pessoas de diferentes organizações podem expressar as fragilidades e limitações percebidas nos parâmetros do GRI e, com base na concordância pública dos entes presentes, novos indicadores são inseridos. Os parâmetros do GRI procuram medir impactos econômicos, sociais, ambientais e de governança de maneira responsável e transparente. Foi elaborado um manual para implantação das diretrizes G4 para relato de sustentabilidade, cuja última atualização foi efetuada em 2013. Esse manual descreve os princípios para definição do conteúdo do relatório, os princípios para assegurar a qualidade do relatório e prevê as seções de conteúdo padrão, quais sejam:

a) Conteúdos padrão gerais: contemplam a estratégia e análise, perfil organizacional, aspectos materiais identificados e limites, engajamento de stakeholders, perfil do relatório, governança, ética e integridade.

b) Conteúdos padrão específicos: orientação para informações sobre a forma de gestão; orientações para indicadores e informações a respeito da forma de gestão relacionadas a aspectos específicos - categoria econômica, categoria ambiental, categoria social, subcategoria práticas trabalhistas e trabalho decente; subcategoria direitos humanos, subcategoria sociedade, subcategoria responsabilidade pelo produto.

Tais diretrizes constituem uma referência internacional para todos os interessados na divulgação de informações acerca da forma de gestão das organizações, seu desempenho ambiental, social e econômico, e impactos nessas áreas. A dimensão econômica da sustentabilidade está associada aos impactos da organização sobre as condições econômicas dos seus stakeholders e sobre os sistemas econômicos em nível local, nacional e global. Esta seção - Dimensão econômica do relatório - não 
tem o objetivo de focar a situação financeira da organização. Nas diretrizes, o termo impacto referese aos aspectos econômicos, sociais e ambientais, sejam eles positivos, negativos, reais, potenciais, diretos, indiretos, de curto prazo, de longo prazo, esperados ou inesperados. A dimensão social dá ênfase às subcategorias práticas trabalhistas e ao trabalho decente, aos direitos humanos, sociedade e responsabilidade pelo produto. E a dimensão ambiental faz alusão a aspectos materiais, energia, água, biodiversidade, emissões, efluentes e resíduos, produtos e serviços, conformidade, transporte, avaliação ambiental de fornecedores, mecanismos de queixas e reclamações relativas a impactos ambientais.

\subsection{Indicadores de fácil monitoramento e mensuração nas empresas}

Com base na leitura do manual, os indicadores foram sistematizados em conformidade com as categorias às quais pertencem, para facilitar a organização das informações no momento em que se elabora o relatório de sustentabilidade, conforme Quadro 1.

Quadro1 -Indicadores relacionados aos conteúdos padrão gerais

\section{CONTEÚDOS PADRÃO GERAIS}

a) Apresente uma declaração do decisor mais graduado da organização acerca da relevância da sustentabilidade para a organização e sua estratégia de sustentabilidade.

b) Faça descrição do perfil da organização; principais impactos, riscos e oportunidades que gera; marcas, produtos e serviços; área de abrangência; natureza da propriedade; mercados em que atua; total de empregados; vendas líquidas; capitalização total; total de ativos; total de empregados; cadeia de fornecedores; associações e organizações nacionais e internacionais das quais participa.

Fonte: A autora (2014)

Os conteúdos de padrão geral estão associados a uma caracterização da organização e do nível de comprometimento desta com a sustentabilidade. Fazem alusão aos stakeholders mais importantes com os quais a organização interage.

Para o caso da organização pesquisada, trata-se de uma prestadora de serviços da área de saúde animal, que comercializa produtos direcionados à sanidade animal e melhoramento da produção. A área de abrangência de atuação é o Brasil. A natureza da propriedade é sociedade empresária limitada. Possui 32 empregados e oferta 34 produtos ao mercado, conforme Quadro 2.

Quadro 2 - Aspectos materiais identificados e limites

Entidades incluídas nas demonstrações financeiras consolidadas ou documentos equivalentes da organização.

Vendas líquidas (para organizações do setor privado) ou receita líquida (para organizações do setor público).

Explique como a organização implementou os Princípios para Definição do Conteúdo do Relatório.

Liste todos os aspectos materiais identificados no processo de definição do conteúdo do relatório.

Para cada aspecto relevante, relate o limite do aspecto dentro da organização, da seguinte maneira:

- Relate se o aspecto é relevante dentro da organização.

- Se o aspecto não for relevante para todas as entidades dentro da organização (como descrito no ponto G4-17), selecione uma das duas seguintes abordagens e apresente:

- A lista de entidades ou grupos de entidades incluídos na G4-17 para os quais o aspecto não é relevante, ou

- A lista de entidades ou grupos de entidades incluídos na G4-17 para os quais o aspecto é relevante. - Relate qualquer limitação específica relacionada ao limite do aspecto dentro da organização.

Para cada aspecto relevante, relate seu limite fora da organização, da seguinte maneira:

- Relate se o aspecto é relevante fora da organização.

- Se o aspecto for relevante fora da organização, identifique as entidades, grupos de entidades ou elementos para os quais o aspecto é relevante. Além disso, descreva a localização geográfica na qual $o$ aspecto é relevante para as entidades identificadas.

- Relate qualquer limitação específica relacionada ao limite do aspecto fora da organização. 
\begin{tabular}{l} 
Relate o efeito de quaisquer reformulações de informações fornecidas em relatórios anteriores e as \\
razões para essas reformulações. \\
\hline $\begin{array}{l}\text { Relate alterações significativas em relação a períodos cobertos por relatórios anteriores em Escopo } \\
\text { e Limites de Aspecto. }\end{array}$ \\
\hline
\end{tabular}

Fonte: A autora (2014)

Quanto aos aspectos materiais identificados e limites, dizem respeito à relevância de cada um dos indicadores para a organização e o seu entorno. A empresa pesquisada não forneceu indicadores para esses aspectos do GRI.

O bloco de indicadores relacionados ao engajamento dos stakeholders tem como propósito descrever todos os stakeholders engajados com a organização e a forma como é construído esse engajamento (Quadro 3). Conforme a empresa pesquisada, há um trabalho intenso que é realizado com os fornecedores e representantes comerciais. Com o cliente, há um estreitamento das parcerias, que ocorre periodicamente, no ato da comercialização dos produtos e fechamento dos pedidos. $\mathrm{O}$ engajamento é feito com os coadjuvantes do processo que são mais relevantes para a organização pesquisada e que impactam diretamente no desempenho obtido. A empresa desenvolve anualmente uma pesquisa de satisfação dos clientes e que em 2013 constatou que a imagem formada pelos clientes é boa. Entretanto, os clientes sugeriram à empresa a realização de visitas da assistência técnica e do pós-venda com maior frequência e também a do vendedor e representante.

Quadro 3 - Engajamento com os stakeholders

\begin{tabular}{|l|}
\hline Apresente uma lista de grupos de stakeholders engajados pela organização. \\
\hline Relate a base usada para a identificação e seleção de stakeholders para engajamento. \\
\hline Relate a abordagem adotada pela organização para envolver os stakeholders, inclusive a frequência \\
do seu engajamento discriminada por tipo egrupo, com uma indicação de que algum engajamento \\
foi especificamente promovido como parte do processo de preparação do relatório. \\
\hline $\begin{array}{l}\text { Relate os principais tópicos e preocupações levantados durante o engajamento de stakeholders } \\
\text { e as medidas adotadas pela organização para abordar esses tópicos e preocupações, inclusive no } \\
\text { processo de relatá-las. Relate os grupos de stakeholders que levantaram cada uma das questões e } \\
\text { preocupações mencionadas. }\end{array}$ \\
\hline
\end{tabular}

Fonte: $A$ autora (2014)

De acordo com o Quadro 4, os indicadores relacionados a ética e integridade dizem respeito à descrição dos valores, princípios, padrões e normas de conduta, integridade e ética adotados pela organização.

Quadro 4 - Ética e integridade

Descreva os valores, princípios, padrões e normas de comportamento da organização, como códigos de conduta e de ética.

Relate os mecanismos internos e externos adotados pela organização para solicitar orientações sobre comportamentos éticos e em conformidade com a legislação, como canais de relacionamento (p. ex.: ouvidoria).

Relate os mecanismos internos e externos adotados pela organização para comunicar preocupações em torno de comportamentos não éticos ou incompatíveis com a legislação e questões relacionadas à integridade organizacional, como encaminhamento de preocupações pelas vias hierárquicas, mecanismos para denúncias de irregularidades ou canais de denúncias.

Fonte: A autora (2014)

A organização pesquisada não possui código de ética formalizado em documento, apenas práticas e rotinas empíricas, que são seguidas pelos colaboradores.

Os indicadores econômicos e ambientais apresentam aspectos importantes para a organização nas esferas da gestão econômica e da gestão ambiental (Quadro 5). A empresa pesquisada não revelou seus indicadores econômicos e ambientais, pois considera que ainda não estão estruturados para serem comunicados aos stakeholders. 
Quadro 5 - Indicadores econômicos e ambientais

Relate o valor econômico direto gerado e distribuído, com base no regime de competência de exercícios, incluindo os componentes básicos das operações globais da organização listados a seguir. Se os dados forem apresentados em regime de caixa, relate a justificativa dessa decisão e os componentes básicos, conforme listados a seguir:

- Valor econômico direto gerado:

- Receitas.

- Valor econômico distribuído:

- Custos operacionais.

- Salários e benefícios de empregados.

- Pagamentos a provedores de capital.

- Pagamentos ao governo (por país).

- Investimentos comunitários.

- Valor econômico retido (calculado como'valor econômico direto gerado' menos 'valor econômico distribuído').

Materiais usados, discriminados por peso ou volume.

Percentual de materiais usados provenientes de reciclagem.

Relate o consumo total de combustíveis oriundos de fontes não renováveis em joules ou em seus múltiplos, inclusive os tipos de combustíveis usados.

Relate o volume total de água retirada das seguintes fontes:

- Águas superficiais, incluindo áreas úmidas, rios, lagos e oceanos.

- Águas subterrâneas.

- Águas pluviais diretamente coletadas e armazenadas pela organização.

- Efluentes de outra organização.

- Abastecimento municipal de água ou outras empresas de abastecimento de água.

a) Relate as emissões indiretas de gases de efeito estufa provenientes da aquisição de energia (Escopo

2) em toneladas métricas de $\mathrm{CO} 2$ equivalente, independentemente de quaisquer negociações de gases de efeito estufa (GEE), como compras, vendas ou transferências de compensações ou licenças.

b) Relate os gases incluídos no cálculo, se essa informação estiver disponível.

c) Relate o ano base escolhido, as justificativas usadas para a sua escolha, emissões no ano base e o contexto de quaisquer mudanças significativas em emissões que geraram a necessidade de recalcular emissões no ano base.

d) Relate as normas, metodologias e premissas adotadas.

e) Relate a fonte dos fatores de emissão usados e as taxas de potencial de aquecimento global (GWP) usadas ou uma referência à fonte de GWP, se essas informações estiverem disponíveis.

f) Relate a abordagem de consolidação escolhida para as emissões (participação acionária, controle financeiro, controle operacional).

Relate o volume total de descartes de água planejados e não planejados por:

- Destinação.

- Qualidade da água, inclusive seu método de tratamento.

- Se a água foi reutilizada por outra organização.

g) Relate as normas, metodologias e premissas adotadas.

Relate o peso total de resíduos perigosos e não perigosos para cada um dos seguintes métodos de disposição:

- Reutilização.

- Reciclagem.

- Compostagem.

- Recuperação, inclusive recuperação de energia.

- Incineração (queima de massa).

- Injeção subterrânea de resíduos.

- Aterro.

- Armazenamento no local.

- Outros (a serem especificados pela organização).

Fonte: A autora (2014)

O Quadro 6 descreve os indicadores relacionados à esfera social. A empresa deve relatar aqueles que são relevantes para a sua gestão. Na referida esfera, a empresa apoiou a Campanha do Agasalho 
de 2014, o pedágio do brinquedo, apoia os atingidos da enchente de junho de 2014, apoia ato público contra violência, apoia a ONG Amigo dos Bichos. Portanto, são ações que foram executadas no passado e continuam sendo efetuadas no ano da pesquisa.

Quadro 6 - Indicadores sociais

Número total e taxas de novas contratações de empregados e rotatividade de empregados por faixa etária, gênero e região.

Benefícios concedidos a empregados de tempo integral que não são oferecidos a empregados temporários ou em regime de meio período, discriminados por unidades operacionais importantes da organização.

Taxas de retorno ao trabalho e retenção após uma licença maternidade/paternidade, discriminadas por gênero.

a) Relate o número total e a taxa de novas contratações de empregados durante o período coberto pelo relatório, discriminados por faixa etária, gênero e região.

b) Relate o número total e a taxa de rotatividade de empregados durante o período coberto pelo relatório, discriminados por faixa etária, gênero e região.

a) Relate os benefícios concedidos regularmente a empregados de tempo integral da organização, mas não a empregados temporários ou em regime de meio período, discriminados por unidades operacionais importantes. Esses benefícios incluem, pelo menos:

- Seguro de vida.

- Plano de saúde.

- Auxílio deficiência e invalidez.

- Licença maternidade/paternidade.

- Fundo de pensão.

- Plano de aquisição de ações.

- Outros.

b) Relate a definição usada para 'unidades operacionais relevantes'.

a) Relate o número total de empregados com direito a tirar licença maternidade/paternidade, discriminado por gênero.

b) Relate o número total de empregados que tiraram licença maternidade/paternidade, discriminado por gênero.

c) Relate o número total de empregados que retornaram ao trabalho após tirar uma licença maternidade/paternidade, discriminado por gênero.

d) Relate o número total de empregados que retornaram ao trabalho após uma licença maternidade/ paternidade e continuaram empregados doze meses após seu retorno ao trabalho, discriminado por gênero.

e) Relate as taxas de retorno ao trabalho e retenção de empregados que tiraram licença maternidade/paternidade, discriminadas por gênero.

a) Relate o prazo mínimo, em semanas, de notificação geralmente dado a empregados e seus representantes eleitos antes da implementação de mudanças operacionais significativas que podem afetá-los substancialmente.

b) Para organizações com acordos coletivos de trabalho, relate se tais acordos especificam um prazo mínimo de notificação e incluem disposições relativas a consultas e negociações.

a) Relate em que nível cada comitê formal de saúde e segurança constituído por empregados de diferentes níveis hierárquicos opera normalmente dentro da organização.

b) Relate o percentual da força de trabalho representada em comitês formais de saúde e segurança constituídos por empregados de diferentes níveis hierárquicos da organização. 
a) Relate os tipos de lesões, a taxa de lesões, a taxa de doenças ocupacionais, dias perdidos, a taxa de absenteísmo e óbitos relacionados ao trabalho para o total de trabalhadores (ou seja, empregados próprios e terceirizados), discriminados por:

- Região.

- Gênero.

b) Relate os tipos de lesões, a taxa de lesões, a taxa de doenças ocupacionais, dias perdidos, a taxa de absenteísmo e óbitos relacionados ao trabalho para autônomos que trabalham no local e cuja segurança geral no ambiente de trabalho é de responsabilidade da organização, discriminados por: - Região.

- Gênero.

c) Relate o sistema de normas aplicado ao registro e relato de estatísticas de acidentes.

a) Relate se há empregados envolvidos em atividades ocupacionais que apresentam alta incidência ou alto risco de doenças específicas.

a) Relate se acordos formais (locais ou globais) com sindicatos abordam tópicos de saúde e segurança.

b) Em caso afirmativo, relate até que ponto, em termos percentuais, os diversos tópicos de saúde e segurança são abordados nesses acordos.

Número médio de horas de treinamento por ano por empregado, discriminadas por gênero e categoria funcional.

Programas de gestão de competências e aprendizagem contínua que contribuem para a continuidade da empregabilidade dos empregados em período de preparação para a aposentadoria.

a) Relate o tipo e escopo de programas implementados e da assistência prestada para aperfeiçoar as habilidades de empregados.

b) Relate os programas de transição oferecidos para facilitar a continuidade da empregabilidade em caso de aposentadoria ou de rescisão de contrato de trabalho.

Percentual de empregados que recebem regularmente análises de desempenho e de desenvolvimento de carreira, discriminado por gênero e categoria funcional.

Relate o percentual do total de empregados, discriminados por gênero e categoria funcional, que receberam avaliação regular de desempenho e de desenvolvimento de carreira durante o período coberto pelo relatório.

Composição dos grupos responsáveis pela governança e discriminação de empregados por categoria funcional, de acordo com gênero, faixa etária, minorias e outros indicadores de diversidade.

a) Relate o percentual de indivíduos que integram os órgãos de governança da organização em cada uma das seguintes categorias de diversidade:

- Gênero.

- Faixa etária: abaixo de 30 anos, de 30 a 50 anos, mais de 50 anos.

- Grupos minoritários.

- Outros indicadores de diversidade, quando relevantes.

b) Relate o percentual de empregados por categoria funcional em cada uma das seguintes categorias de diversidade:

- Gênero

- Faixa etária: abaixo de 30 anos, de 30 a 50 anos, mais de 50 anos.

- Grupos minoritários.

- Outros indicadores de diversidade, quando relevantes.

Razão matemática do salário e remuneração entre mulheres e homens, discriminada por categoria funcional e unidades operacionais relevantes.

a) Relate a razão matemática entre o salário e a remuneração base para mulheres e homens em cada categoria funcional, discriminada por unidades operacionais importantes.

b) Relate a definição usada para 'unidades operacionais relevantes'.

Percentual de novos fornecedores selecionados com base em critérios relativos a práticas trabalhistas. 
Impactos negativos significativos reais e potenciais para as práticas trabalhistas na cadeia de fornecedores e medidas tomadas a esse respeito.

a) Relate o número de fornecedores submetidos a avaliações de impactos em relação às práticas trabalhistas.

b) Relate o número de fornecedores que geram impactos negativos significativos reais e potenciais relativamente às práticas trabalhistas.

c) Relate os impactos negativos significativos reais e potenciais para as práticas trabalhistas identificados na cadeia de fornecedores.

d) Relate o percentual de fornecedores que geram impactos negativos significativos reais e potenciais sobre práticas trabalhistas com os quais melhorias foram acordadas com base em avaliações.

e) Relate o percentual de fornecedores que geram impactos negativos significativos reais e potenciais em relação às práticas trabalhistas que tiveram contratos rescindidos com base em avaliações e os motivos dessa medida.

Número de queixas e reclamações relacionadas a práticas trabalhistas registradas, processadas e solucionadas por meio de mecanismo formal de queixas e reclamações.

a) Relate o número total de queixas e reclamações relacionadas a práticas trabalhistas registradas por meio de mecanismos formais de queixas e reclamações durante o período coberto pelo relatório.

b) Entre as queixas e reclamações identificadas, relate quantas delas foram:

- Processadas durante o período coberto pelo relatório.

- Solucionadas durante o período coberto pelo relatório.

c) Relate o número total de queixas e reclamações relacionadas a práticas trabalhistas registradas antes do período coberto pelo relatório que foram solucionadas nesse período.

Fonte: A autora (2014)

O Quadro 7, que apresenta os indicadores relacionados aos direitos humanos, faz alusão aos requisitos legais dos colaboradores e stakeholders da organização.

A empresa contrata os colaboradores com carteira assinada e os representantes comerciais são comissionados. Outros aspectos relacionados a direitos humanos não foram revelados pela empresa.

Quadro 7 - Indicadores relacionados aos direitos humanos

Número total e percentual de acordos e contratos de investimentos significativos que incluem cláusulas de direitos humanos ou que foram submetidos à avaliação referente a direitos humanos. a) Relate o número total e percentual de acordos e contratos de investimentos significativos que incluem cláusulas de direitos humanos ou que foram submetidos à avaliação referente a direitos humanos.

b) Relate a definição de 'acordos de investimentos significativos' usada pela organização.

Número total de horas de treinamento de empregados em políticas de direitos humanos ou procedimentos relacionados a aspectos dos direitos humanos relevantes para as operações da organização, incluindo o percentual de empregados treinados.

a) Relate o número total de horas dedicadas, no período coberto pelo relatório, a treinamento em políticas de direitos humanos ou procedimentos relacionados a aspectos dos direitos humanos relevantes para as operações da organização.

b) Relate o percentual de empregados treinados, no período coberto pelo relatório, em políticas de direitos humanos ou procedimentos relacionados a aspectos dos direitos humanos relevantes para as operações da organização.

Número total de casos de discriminação e medidas corretivas tomadas.

a) Relate o número total de casos de discriminação ocorridos durante o período coberto pelo relatório.

b) Relate a situação atual dos casos e as providências tomadas com referência ao seguinte:

- A organização analisou o caso.

- Um plano de reparação está sendo implementado.

- O plano de reparação foi implementado e seus resultados analisados por meio de processos rotineiros de análise da gestão interna.

- O caso não está mais sujeito a medidas corretivas. 
Operações e fornecedores identificados em que o direito de exercer a liberdade de associação e a negociação coletiva possa estar sendo violado ou haja risco significativo, e as medidas tomadas para apoiar esse direito.

a) Relate operações e fornecedores em que o direito de exercer a liberdade de associação e a negociação coletiva pode estar sendo violado ou estar correndo risco de violação, discriminados por:

- Tipo de operação (p. ex.: fábrica) e fornecedor.

- Países ou áreas geográficas com operações e fornecedores considerados em situação de risco.

b) Relate as medidas tomadas pela organização no período coberto pelo relatório no sentido de apoiar o exercício da liberdade de associação e da negociação coletiva.

Operações e fornecedores identificados como de risco para a ocorrência de casos de trabalho infantil e medidas tomadas para contribuir para a efetiva erradicação do trabalho.

a) Relate as operações e fornecedores que possam apresentar riscos significativos de ocorrência de casos de:

- Trabalho infantil.

- Empregados jovens expostos a trabalho perigoso.

b) Relate as operações e fornecedores que possam apresentar riscos significativos de ocorrência de casos de trabalho infantil, discriminados por:

- Tipo de operação (p. ex.: fábrica) e fornecedor.

- Países ou áreas geográficas com operações e fornecedores considerados em situação de risco.

c) Relate as medidas tomadas pela organização durante o período coberto pelo relatório para contribuir para a efetiva erradicação do trabalho infantil.

Operações e fornecedores identificados como de risco significativo para a ocorrência de trabalho forçado ou análogo ao escravo e medidas tomadas para contribuir para a eliminação de todas as formas de trabalho forçado ou análogo ao escravo.

a) Relate as operações e fornecedores que apresentam riscos significativos de ocorrência de casos de trabalho forçado ou obrigatório, discriminados por:

- Tipo de operação (p. ex.: fábrica) e fornecedor.

- Países ou áreas geográficas com operações e fornecedores considerados em situação de risco.

b) Relate as medidas tomadas pela organização durante o período coberto pelo relatório para contribuir para a eliminação de todas as formas de trabalho forçado ou análogo ao escravo.

Percentual do pessoal de segurança que recebeu treinamento nas políticas ou procedimentos da organização relativos a direitos humanos que sejam relevantes às operações.

a) Relate o percentual do pessoal de segurança que recebeu treinamento formal nas políticas ou procedimentos específicos de direitos humanos da organização e sua aplicação na segurança.

b) Relate se os requisitos de treinamento também se aplicam a empresas contratadas para fornecer pessoal de segurança.

Número total de casos de violação de direitos de povos indígenas e tradicionais e medidas tomadas a esse respeito.

a) Relate o número total de casos identificados de violação de direitos de povos indígenas no decorrer do período coberto pelo relatório.

b) Relate a situação atual dos casos e as medidas tomadas com referência ao seguinte:

- A organização analisou o caso.

- Um plano de reparação está sendo implementado.

- O plano de reparação foi implementado e seus resultados analisados por meio de processos rotineiros de análise da gestão interna.

- O caso não está mais sujeito a medidas corretivas.

Número total e percentual de operações submetidas a análises ou avaliações de direitos humanos de impactos relacionados a direitos humanos.

Percentual de novos fornecedores selecionados com base em critérios relacionados a direitos humanos. 
Impactos negativos significativos reais e potenciais em direitos humanos na cadeia de fornecedores e medidas tomadas a esse respeito.

a) Relate o número de fornecedores submetidos a avaliações de impactos em direitos humanos.

b) Relate o número de fornecedores identificados que podem gerar impactos negativos significativos reais e potenciais sobre direitos humanos.

c) Relate os impactos negativos significativos reais e potenciais em direitos humanos identificados na cadeia de fornecedores.

d) Relate o percentual de fornecedores identificados que podem gerar impactos negativos significativos reais e potenciais sobre direitos humanos com os quais melhorias foram acordadas com base em avaliações.

e) Relate o percentual de fornecedores identificados que podem gerar impactos negativos significativos reais e potenciais em direitos humanos com os quais os contratos foram rescindidos com base em avaliações e a razão dessa medida.

Número de queixas e reclamações relacionadas a impactos em direitos humanos registradas, processadas e solucionadas por meio de mecanismo formal de queixas e reclamações.

a) Relate o número total de queixas e reclamações relacionadas a impactos em direitos humanos registradas por meio de mecanismos formais de queixas e reclamações durante o período coberto pelo relatório.

b) Entre as queixas e reclamações identificadas, relate quantas delas foram:

- Processadas no período coberto pelo relatório.

- Solucionadas no período coberto pelo relatório.

c) Relate o número total de queixas e reclamações relacionadas a impactos em direitos humanos registradas antes do período coberto pelo relatório que foram solucionadas durante esse período.

Fonte: A autora (2014)

Os indicadores relacionados no bloco sociedade (Quadro 8) fazem alusão aos impactos positivos e negativos que são causados pela organização no entorno do local onde está localizada. Nada foi declarado com relação a esses indicadores.

Quadro 8 - Indicadores relacionados à sociedade

Percentual de operações com programas implementados de engajamento da comunidade local, avaliação de impactos e desenvolvimento local.

a) Relate o percentual de operações que implementaram programas de engajamento da comunidade, de avaliação de impactos e de desenvolvimento local, incluindo, entre outros, o uso de:

- Avaliações de impactos sociais, inclusive avaliações de impactos de gênero, com base em processos participativos.

- Avaliações de impactos ambientais e monitoramento contínuo.

- Divulgação pública dos resultados de avaliações de impactos ambientais e sociais.

- Programas de desenvolvimento local baseados nas necessidades de comunidades locais.

- Planos de engajamento de stakeholders baseados em mapeamentos dessas partes.

- Comitês e processos de consulta ampla à comunidade local, incluindo grupos vulneráveis.

- Conselhos de trabalho, comissões de saúde e segurança no trabalho e outras entidades representativas de empregados para discutir impactos.

- Processos formais de queixas e reclamações por parte de comunidades locais.

Operações com impactos negativos significativos reais e potenciais nas comunidades locais.

a) Relate as operações com impactos negativos significativos reais e potenciais em comunidades locais, incluindo:

- A localização das operações.

- Os impactos negativos significativos reais e potenciais das operações.

Número total e percentual de operações submetidas a avaliações de riscos relacionados à corrupção e os riscos significativos identificados.

a) Relate o número total e percentual de operações submetidas a avaliações de riscos relacionados à corrupção.

b) Relate os riscos significativos relacionados à corrupção identificados com base em avaliações de riscos. 
Comunicação e treinamento em políticas e procedimentos de combate à corrupção.

a) Relate o número total e percentual de membros do órgão de governança aos quais foram comunicadas as políticas e procedimentos anticorrupção adotados pela organização, discriminados por região.

b) Relate o número total e percentual de empregados aos quais foram comunicadas as políticas e procedimentos anticorrupção adotados pela organização, discriminados por categoria funcional e região.

c) Relate o número total e percentual de parceiros comerciais aos quais foram comunicadas as políticas e procedimentos anticorrupção adotados pela organização, discriminados por tipo de parceiro e região.

d) Relate o número total e percentual de membros do órgão de governança que receberam treinamento no combate à corrupção, discriminados por região.

e) Relate o número total e percentual de empregados que receberam treinamento no combate à corrupção, discriminados por categoria funcional e região.

Casos confirmados de corrupção e medidas tomadas.

a) Relate o número total e a natureza dos casos confirmados de corrupção.

b) Relate o número total de casos confirmados em que empregados foram demitidos ou punidos por corrupção.

c) Relate o número total de casos confirmados em que contratos com parceiros comerciais foram rescindidos ou não renovados em decorrência de violações relacionadas à corrupção.

d) Relate quaisquer processos judiciais públicos relacionados à corrupção movidos contra a organização ou seus empregados no período coberto pelo relatório e o resultado desses processos.

Valor total de contribuições para partidos políticos e políticos, discriminado por país e destinatário/ beneficiário.

a) Relate o valor monetário total de contribuições para partidos políticos e políticos em dinheiro e em espécie feitas pela organização direta ou indiretamente, discriminado por país e destinatário/ beneficiário.

b) Relate como o valor monetário de contribuições em espécie foi estimado, conforme o caso.

Número total de ações judiciais movidas por concorrência desleal, práticas de truste e monopólio e seus resultados.

a) Relate o número total de ações judiciais pendentes ou encerradas durante o período coberto pelo relatório referentes à concorrência desleal e a violações de leis antitruste e da regulamentação de monopólio em que a organização tenha sido identificada como participante.

b) Relate os principais resultados das ações judiciais concluídas, incluindo quaisquer decisões ou sentenças.

Valor monetário de multas significativas e número total de sanções não monetárias aplicadas em decorrência da não conformidade com leis e regulamentos.

a) Relate multas e sanções não monetárias significativas nos seguintes termos:

- Valor monetário total de multas significativas.

- Número total de sanções não monetárias.

- Processos movidos por meio de mecanismos de arbitragem.

b) Se a organização não tiver identificado nenhum caso de não observância de leis ou regulamentos, uma breve declaração desse fato será suficiente.

c) Relate o contexto em que multas significativas e sanções não monetárias foram aplicadas.

Percentual de novos fornecedores selecionados com base em critérios relativos a impactos na sociedade. 
Impactos negativos significativos reais e potenciais da cadeia de fornecedores na sociedade e medidas tomadas a esse respeito.

a) Relate o número de fornecedores submetidos a avaliações de impactos na sociedade.

b) Relate o número de fornecedores identificados que podem gerar impactos negativos significativos, efetivos ou potenciais, na sociedade.

c) Relate os impactos negativos significativos, efetivos ou potenciais, para a sociedade, identificados na cadeia de fornecedores.

d) Relate o percentual de fornecedores identificados que podem gerar impactos negativos significativos, efetivos ou potenciais, para a sociedade com os quais melhorias foram acordadas com base em avaliações.

e) Relate o percentual de fornecedores identificados que podem gerar impactos negativos significativos, efetivos ou potenciais, para a sociedade com os quais contratos foram encerrados como resultado da avaliação e a razão dessa medida.

Número de queixas e reclamações relacionadas a impactos na sociedade registradas, processadas e solucionadas por meio de mecanismo formal de queixas e reclamações.

a) Relate o número total de queixas e reclamações relacionadas a impactos na sociedade registradas por meio de mecanismos formais de queixas e reclamações durante o período coberto pelo relatório.

b) Entre as queixas e reclamações identificadas, relate quantas delas foram:

- Processadas durante o período coberto pelo relatório.

- Solucionadas durante o período coberto pelo relatório.

c) Relate o número total de queixas e reclamações relacionadas a impactos na sociedade registradas antes do período coberto pelo relatório que foram solucionadas nesse período.

Fonte: A autora (2014)

O bloco relacionado à saúde e segurança do cliente (descrito no Quadro 9), apresenta um conjunto de indicadores relacionados aos stakeholders externos com os quais a empresa interage. Deve ser feito alusão aos stakeholders relevantes para o contexto organizacional em que a empresa vive.

Quadro 9 - Indicadores relacionados à saúde e segurança do cliente

Percentual de categorias de produtos e serviços significativas para as quais são avaliados impactos na saúde e segurança, buscando melhorias.

Número total de casos de não conformidade com regulamentos e códigos voluntários relacionados aos impactos causados por produtos e serviços na saúde e segurança durante seu ciclo de vida, discriminados por tipo de resultado.

a) Relate o número total de casos de não conformidade com regulamentos e códigos voluntários relacionados aos impactos gerados por produtos e serviços na saúde e segurança durante o período coberto pelo relatório, discriminados por:

- Casos de não conformidade com regulamentos que resultaram na aplicação de multa ou penalidade.

- Casos de não conformidade com regulamentos que resultaram em advertência.

- Casos de não conformidade com códigos voluntários.

b) Se a organização não tiver identificado nenhum caso de não conformidade com regulamentos e códigos voluntários, uma breve declaração desse fato será suficiente. 
Tipo de informações sobre produtos e serviços exigidas pelos procedimentos da organização referentes a informações e rotulagem de produtos e serviços, e percentual de categorias significativas sujeitas a essas exigências.

a) Relate se as seguintes informações sobre produtos e serviços são exigidas pelos procedimentos da organização relativos a informações e rotulagem de produtos e serviços: (sim ou não), Terceirização de componentes do produto ou serviço.

Conteúdo, particularmente, de substâncias que possam gerar impactos ambientais ou sociais. A empresa pesquisa presta um serviço à sociedade.

A prestação de serviços pode ser ofertada pela própria empresa ou contratar uma empresa terceirizada para fazer parte dele (por exemplo, contrata-se um caminhão de um profissional autônomo que vai fazer a entrega do produto que é comercializado, contrata-se um profissional específico que vai dar uma palestra sobre o produto comercializado).

Uso seguro do produto ou serviço.

Disposição do produto e impactos ambientais/sociais.

Outras (explique).

b) Relate o percentual de categorias de produtos ou serviços significativos cobertas e avaliadas em conformidade com os procedimentos da organização.

Número total de casos de não conformidade com regulamentos e códigos voluntários relativos a informações e rotulagem de produtos e serviços, discriminados por tipo de resultados.

a) Relate o número total de casos de não conformidade com regulamentos e códigos voluntários relativos a informações e rotulagem de produtos e serviços, discriminados por:

- Casos de não conformidade com regulamentos que resultaram na aplicação de multa ou penalidade.

- Casos de não conformidade com regulamentos que resultaram em advertência.

- Casos de não conformidade com códigos voluntários.

b) Se a organização não tiver identificado nenhum caso de não conformidade com regulamentos e códigos voluntários, uma breve declaração desse fato será suficiente.

Resultados de pesquisas de satisfação do cliente.

a) Relate os principais resultados ou conclusões de pesquisas de satisfação do cliente (com base em amostragens estatisticamente relevantes) realizadas no período coberto pelo relatório referentes a informações sobre:

- A organização.

- Uma categoria importante de produtos ou serviços.

- Locais significativos de operações.

Venda de produtos proibidos ou contestados.

Número total de casos de não conformidade com regulamentos e códigos voluntários relativos a comunicações de marketing, incluindo publicidade, promoção e patrocínio, discriminados por tipo de resultados.

a) Relate o número total de casos de não conformidade com regulamentos e códigos voluntários relativos a comunicações de marketing, incluindo publicidade, promoção e patrocínios, discriminados por:

- Casos de não conformidade com regulamentos que resultaram na aplicação de multa ou sanção.

- Casos de não conformidade com regulamentos que resultaram em advertência.

- Casos de não conformidade com códigos voluntários.

b) Se a organização não tiver identificado nenhum caso de não conformidade com regulamentos e códigos voluntários, uma breve declaração desse fato será suficiente. 
Número total de queixas comprovadas relativas à violação de privacidade e perda de dados de clientes.

a) Relate o número total de queixas comprovadas relativas à violação de privacidade do cliente, categorizadas por:

- Queixas recebidas de partes externas e comprovadas pela organização.

- Queixas de agências reguladoras.

b) Relate o número total de vazamentos, furtos ou perdas de dados de clientes que foram identificados.

c) Se a organização não tiver identificado nenhuma queixa comprovada, uma breve declaração desse fato será suficiente.

Valor monetário de multas significativas aplicadas em virtude de não conformidade com leis e regulamentos relativos ao fornecimento e uso de produtos e serviços.

a) Relate o valor monetário total de multas significativas por não conformidade com leis e regulamentos relativos ao fornecimento e uso de produtos e serviços.

b) Se a organização não tiver identificado nenhum caso de não observância de leis ou regulações, uma breve declaração desse fato será suficiente.

Fonte: A autora (2014)

\subsection{Procedimentos operacionais em uma empresa de pequeno ou de médio porte}

Para implantar um relatório de sustentabilidade em pequenas ou médias empresas, é imprescindível:

- O diretor-presidente ter o desejo de registrar o desempenho sustentável via relatório e assumir a liderança do processo de implantação.

- Criar o Comitê de sustentabilidade na empresa, composto por aproximadamente três pessoas (para envolver nível estratégico, tático, operacional, considerado pelo GRI número mínimo de sujeitos para deliberar). Esse comitê deve desenvolver o planejamento das ações que serão desenvolvidas para elaboração do relatório de sustentabilidade.

- Comunicar a todos os colaboradores a decisão e treiná-los, para que estejam aptos a implantar e monitorar os indicadores de sustentabilidade relacionados ao seu setor.

- Definir uma pessoa que compilará todos os materiais e que assessorará aquelas equipes que tiverem dificuldades em preencher a planilha em Excel.

- Elaborar formulários e/ou planilhas específicos para registrar e monitorar os dados.

- Fazer uma reunião mensal para avaliar o previsto e o realizado por área/setor de avaliação. Posteriormente, criar planos de ação para contornar possíveis contingências que sobrevêm ao processo de tabulação dos indicadores de sustentabilidade.

- Acompanhar, monitorar e relatar continuamente os indicadores relevantes para a gestão da organização.

- Descritos os indicadores, ser definidas metas de melhoria contínua dos indicadores descritos. Essas metas podem ser em percentuais. A cada ano deve ser avaliado se o indicador foi atingido e quais as explicações para o atingimento ou não daqueles resultados. Além disso, novos parâmetros devem ser definidos como meta.

- A elaboração dos registros para produção do relatório de sustentabilidade não pode ser um complicador para o setor, mas fazer parte da rotina de atividades. Portanto, os colaboradores devem ser conscientizados dos benefícios associados à adoção de um relatório de sustentabilidade.

- A organização deve focar naqueles indicadores que são relevantes para a sua gestão. Os demais não há necessidade de serem relatados.

- A partir do segundo ano de elaboração do relatório de sustentabilidade, a empresa deve fazer comparativos dos resultados obtidos em relação ao ano anterior; e a partir do terceiro ano, apresentar o comparativo dos resultados do triênio.

- A organização deve relatar a opção 'de acordo' escolhida pela organização no momento de descrever o relatório. Há duas opções possíveis: (a) Essencial: Listar todos os tópicos materiais e pelo menos um indicador de cada item. (b) Abrangente: Listar todos os tópicos materiais e todos os indicadores materiais. Nas duas versões, a empresa deve relatar como definiu a materialidade. Podese ainda declarar: referenciado em GRI G4 - caso a empresa utilize o G4, mas não atenda a todos os requisitos. Esse novo enfoque na materialidade significa que os relatórios de sustentabilidade enfocarão questões efetivamente cruciais para a consecução das suas metas e gestão do seu impacto 
Simone Sehnem; Maiara Cristina Lukas; Patrícia do Desterro Marques

na sociedade. Aspectos materiais são aqueles que refletem os impactos econômicos, ambientais e sociais significativos da organização ou influenciam substancialmente as avaliações e decisões de stakeholders.

Portanto, a elaboração de um relatório de sustentabilidade é um processo simples, que requer o desejo para iniciar e disciplina para monitorar os parâmetros relevantes para a organização.

\subsection{Discussão dos resultados}

A elaboração de um relatório de sustentabilidade é decorrente de um processo de engajamento de stakeholders adotados pela organização em suas atividades correntes. É importante documentar os processos e a abordagem adotada no processo de tomada de decisões. Para que isso seja possível, é necessário e imprescindível que haja recursos humanos capacitados e disponíveis para desenvolver tais ações.

É preciso engajar os stakeholders para buscar a conformidade de normas internacionalmente conhecidas e para informar processos organizacionais, e comerciais. O engajamento dos stakeholders pode ser adotado também para informar o processo de elaboração do relatório de sustentabilidade.

O relatório deve ser elaborado, seguindo os princípios para definir o conteúdo, quais sejam, contexto da sustentabilidade, inclusão de stakeholders, materialidade e completude. Para definir a qualidade do documento, o GRI prevê que a organização deve seguir os princípios do equilíbrio, tempestividade, clareza, comparabilidade, exatidão e confiabilidade.

No caso da empresa pesquisada, há esse desejo de implantar um relatório de sustentabilidade. Entretanto, falta direcionar recursos humanos aptos e dispostos a implementar os indicadores necessários a fim de gerar tal relatório. A alta administração precisa impor algumas iniciativas e comunicar a todos os colaboradores da importância e necessidade de monitorá-los. A falta de informação sistematizada em conformidade com os aspectos preconizados pelo GRI tornou-se um limitador para esta pesquisa. Foram mínimas as informações repassadas pela empresa. Portanto, não basta ter apenas o desejo de criar um relatório de sustentabilidade, mas precisa haver um envolvimento e comprometimento da equipe para que esse desejo torne-se exequível.

\section{CONSIDERAÇÕES FINAIS}

O propósito deste estudo consistiu em descrever os procedimentos operacionais para a elaboração de um relatório de sustentabilidade para pequenas e médias empresas. Trata-se de procedimentos de acompanhamento e monitoramento de um conjunto de indicadores relacionados a aspectos econômicos, sociais, ambientais e de governança da empresa, e o desejo consciente da organização pela busca constante de melhoria contínua e de disciplina para acompanhar e relatar os parâmetros considerados relevantes para a gestão da organização.

Quanto às diretrizes do GRI para elaborar um manual de procedimentos operacionais, para implantação de um relatório de sustentabilidade em pequenas e médias empresas, são relevantes, para a marca, a reputação e a credibilidade da organização. São diretrizes fundamentais para a qualidade da gestão e a qualidade da governança. Além disso, devem fazer alusão ao respeito aos direitos humanos, ao respeito ao meio ambiente, à boa relação com a comunidade e à boa relação com os trabalhadores. Até porque o propósito é monitorar indicadores que sejam relevantes para a gestão e é fato que não se gerencia aquilo que não se mede.

No que diz respeito aos formulários/planilhas de controle para geração de indicadores que permitam elaborar um relatório de sustentabilidade em pequenas e médias empresas industriais e prestadoras de serviços, devem ser simples, de fácil manuseio e com vocabulário compatível ao nível de formação dos colaboradores. No caso descrito, foram adotados a planilha Excel e os formulários em formato Word, plataformas conhecidas pelos colaboradores da empresa na qual foi validada a pesquisa de acordo com o depoimento dos pesquisados.

Sobretudo, é preciso preparar a empresa, para que se torne apta a monitorar indicadores de desempenho nas diversas dimensões preconizadas pelo GRI.

As limitações da pesquisa estão associadas aos fatos de os indicadores do GRI serem considerados complexos para uma pequena empresa, pois esta não tem por hábito monitorar a maioria dos indicadores descrito nessa diretriz. Isso dificultou a finalização da pesquisa com a consistência de dados empíricos esperada.

As recomendações para futuros estudos na área estão associadas ao trabalho de comunicação 
a ser desenvolvido em associações comerciais locais, para apresentar a importância de um relatório de sustentabilidade para uma pequena e média empresa. Os gestores das organizações precisam conhecer a importância e os impactos decorrentes da elaboração de um relatório de sustentabilidade, para que se sintam motivados a implantá-lo em suas empresas.

\title{
ELABORATION AND APPLICATION OF SUSTAINABILITY INDICATORS IN SMALL AND MEDIUM SIZE COMPANIES
}

\begin{abstract}
This text aims to describe the operational procedures for the elaboration of a sustainability report for small and medium size companies based on the Global Reporting Initiative (GRI) guidelines. The study was developed in a service provider company located in Chapecó - SC. It is a descriptive and qualitative research and the data was collected in the first semester of 2014. Results showed that the difficulties in the elaboration of a sustainability report in a small company are great due to the lack of human resources to monitor indicators. For such enterprise to be successful, it is necessary to inform the members of the team about the importance and need to follow the performance indicators of the economic, social and environmental areas. Besides, the strategic area of the organization has to be directly involved in the process in order to legitimate the idea in the organizational context.

We suggested the creation of a sustainability committee to be coordinated by the director of the company who will promote the engagement of all collaborators in the creation of a culture of sustainability. The next step is the training and monitoring of indicators which are relevant for the management. Next, all registers have to bemade and tabulated in a report format for subsequent communication to all parts involved in the process. An Excel spreadsheet is to be adopted as a tool and it will stress the indicators, their measurement metrics and the monthly performance achieved by the organization. In possession of all data, it is possible to elaborate a sustainability report and create goals for continuous improvement.
\end{abstract}

Keywords: Sustainability. Global Report Initiative. Sustainability Report.

\section{REFERÊNCIAS}

ABDALLA, José Jorge; FEICHAS, Susana Arcangela Quacchia. Modelo Hackefors para obtenção de certificado ambiental ISO-14.001 em pequenas e médias empresas: uma discussão sobre sua aplicação em empresas brasileiras. Cad. EBAPE.BR, Rio de Janeiro, v. 3, n. 3, p. 1-14,2005.

ALMEIDA JUNIOR, Antônio Ribeiro de; GOMES, Helena Lemos dos Reis Magalhães. Gestão ambiental e interesses corporativos: imagem ambiental ou novas relações com o ambiente? Ambient. soc., São Paulo, v. 15, n. 1, p. 157-177, 2012.

BELLEN, H.M.V. Indicadores de sustentabilidade: uma análise comparativa. Rio de Janeiro: FGV, 2008.

BONACCHI, M; RINALDI, L. A performance measurement system for sustainability. In: EPSTEIN, Marc J.; MANZONI, Jean-François. Performance measurement and management control: improving organization and society studies in managerial and financial accounting. Houstoun: Emerald Group Publishing Limited, 2006. p. 49-77.

CALLADO, Aldo Leonardo Cunha; FENSTERSEIFER, Jaime Evaldo. Indicadores de sustentabilidade. In: ALBUQUERQUE, José de Lima. Gestão ambiental e responsabilidade social: conceitos, ferramentas e aplicações. São Paulo: Atlas, 2009. p. 212-234.

HAHN, Rüdiger; LULFS, Regina. Corporate Social Responsiveness: Exploring the Dynamics of "Bad Episodes".Disponível em <https://ideas.repec.org/a/eee/eurman/v23y2005i5p495-506.html>. Acesso em: 12 dez. 2014.

HALLINAM, P; JENKS, R. The battle against environmental performance - the Hackefors model in Sweden. 2004. 187 f.Thesis (Master) - International Business Programme, Linkopings Universitet, Suécia, 2004. 
MILNE, Markus; GRAY, Rob. W(h)ither Ecology? The Triple. Journal of Business Ethics, Canadá,v. 118, n. 1, p. 13-29,Nov. 2013.

MOURA, L. G. V. Indicadores para a avaliação da sustentabilidade em sistemas de produção da agricultura familiar: o caso dos fumicultores de Agudo no Rio Grande do Sul. 2002.

249f. Dissertação(Mestrado em Desenvolvimento Rural). Programa de Pós-Graduação em Desenvolvimento Rural (PGDR) - Universidade Federal do Rio Grande do Sul, Porto Alegre, 2002.

SEARCY, C; KARAPETROVIC, S; MCCARTNEY, D. Designing sustainable development indicators: analysis for a case utility. Measuring Business Excelence, China, v.9, n.2, p.33-41,2005.

TOPPINEN, Anne et al. Corporate Social Responsibility \& Environmental Management, Estados Unidos,v. 19,n. 4, p. 191-205, Jul./Aug. 2012.Disponível em:<http://research.lut.fi/converis-lut/ publicweb/person/8930;jsessionid=bf7609aad1580efe727437c79996?show=PUBLICATION\&publye ar=\&type=All\&startDate=\&endDate=\&lang=1 > . Acesso em: 14 dez. 2014.

VELEVA, V; ELLENBECKER, M. A proposal for measuring business sustainability: addressing shortcomings in existing frameworks. Greener management international, Reino Unido, n.31, p.101-120, autumn 2000.Disponível em:<http://www.greenleaf-publishing.com/default. asp?ContentID=8>. Acesso em: 14 dez. 2014. 